\title{
Associations between adherence and outcomes among older, type 2 diabetes patients: evidence from a Medicare Supplemental database
}

This article was published in the following Dove Press journal:

Patient Preference and Adherence

16 August 2016

Number of times this article has been viewed

\author{
Kristina Secnik Boye' \\ Sarah E Curtis' \\ Maureen J Lage ${ }^{2}$ \\ Luis-Emilio Garcia-Perez ${ }^{3}$ \\ 'Global Patient Outcomes and \\ Real World Evidence, Eli Lilly and \\ Company, Lilly Corporate Center, \\ Indianapolis, IN, ${ }^{2} \mathrm{HealthMetrics}$ \\ Outcomes Research, LLC, Bonita \\ Springs, FL, ${ }^{3}$ Global Medical Affairs, \\ Lilly Diabetes, Eli Lilly and Company, \\ Lilly Corporate Center, Indianapolis, \\ IN, USA
}

Objective: To examine the association between adherence to glucose-lowering agents and patient outcomes, including costs, acute-care resource utilization, and complications, in an older, type 2 diabetic population.

Data and methods: The study used Truven's Medicare Supplemental database from July 1, 2009 to June 30, 2014. Patients aged 65 years or older were included if they had at least two type 2 diabetes diagnoses and received a glucose-lowering agent from July 1, 2010 through June 30, 2011. Multivariable analyses examined the relationships among 3-year patient outcomes and levels of adherence, proxied by the proportion of days covered. Outcomes included all-cause medical costs, diabetes-related medical costs, acute-care resource utilization, and acute complications.

Results: In this study (N=123,235), higher adherence was linked to reduced costs and improved health outcomes. For example, comparing an individual with adherence of proportion of days covered $<20 \%$ to one with proportion of days covered $\geq 80 \%$ illustrates an average saving of $\$ 28,824$ in total 3-year costs. Furthermore, a 1\% increase in adherence among 1,000 patients was associated with all-cause savings of $\$ 65,464$ over 3 years. The probability of a hospitalization, an emergency room (ER) visit, or an acute complication decreased monotonically as adherence levels got higher, as did the number of hospitalizations, ER visits, and days hospitalized $(P<0.005)$.

Conclusion: Higher adherence was associated with substantially less need for acute care, as indicated by a lowered probability of hospitalization or ER use, a reduced risk of an acute complication, and a decreased number of hospitalizations, ER visits, and days hospitalized. Higher adherence was also generally associated with lower all-cause and diabetes-related total costs, despite higher drug costs. These lower total costs were driven by the diminished acute care and outpatient costs. Results suggest that higher glucose-lowering agent adherence is associated with significant benefits for payers and older patients with type 2 diabetes.

Keywords: proportion of days covered, complications, costs, resource utilization, retrospective study

\section{Introduction}

The world population is aging at an unprecedented and accelerating rate. ${ }^{1}$ Correspondingly, the US population is aging faster than at any other time in history, ${ }^{2}$ with the current number of Americans aged 65 years or older projected to more than double to 98 million by $2060 .{ }^{3}$ Older age is a nonmodifiable risk factor for a number of chronic diseases, including type 2 diabetes (T2D)., ${ }^{4,5}$ In the US, the 65 and older demographic has approximately twice the rate of diabetes relative to the overall adult population $(25.9 \%$ vs $12.3 \%){ }^{6}$
Correspondence: Maureen J Lage HealthMetrics Outcomes Research, 27576 River Reach Drive, Bonita Springs, FL 34I34, USA

Tel +l 8602450685

Email lagemj@hlthmetrics.com 
Diabetes is especially burdensome in later life. Older persons with the disease have worse health, greater disability, and a higher risk of institutionalization relative to seniors without it. ${ }^{7,8}$ Additionally, seniors with diabetes have higher all-cause death rates compared to the general public ${ }^{9}$ and more diabetes-related resource use, costs, and death relative to the overall population with diabetes..$^{10}$ In economic terms, the average, annual, excess expenditures related to diabetes are approximately three times as high for an older patient relative to a patient under 45 years of age $(\$ 11,825$ vs $\$ 4,394)$ and approximately twice as high relative to an individual 45 to 64 years of age $(\$ 11,825$ vs $\$ 5,611) .{ }^{10}$ Given that T2D accounts for $90 \%-95 \%$ of adult cases of diabetes, ${ }^{6}$ the majority of this burden is due to T2D.

Current guidelines for the treatment of diabetes among older patients suggest a multifaceted approach that includes glucose-lowering pharmaceutical therapy, ${ }^{11}$ and a number of studies have suggested that T2D patients can substantially mitigate various adverse outcomes simply by taking their medication as prescribed. For instance, higher adherence rates for glucose-lowering agents (GLAs) have been shown to reduce hospitalizations and/or emergency room (ER) visits, ${ }^{12-17}$ complications, ${ }^{13,18,19}$ and costs. ${ }^{14,17,20-23}$ However, limited research has focused on adherence among older patients with $\mathrm{T} 2 \mathrm{D},{ }^{17,24}$ and relatively few studies have had a broad enough scope to encompass all classes of GLAs, much less the newer GLAs. ${ }^{14-16,19,22}$

Given the aging of the US population as well as the high prevalence and burden of T2D among American seniors, the present study used a large claims database to examine relationships among GLA adherence and costs, acute-care resource utilization, and acute complications in a population of older patients insured through a Medicare Supplemental plan. Specifically, the analysis examines the hypothesis that higher adherence, as proxied by the proportion of days covered (PDC), is associated with reduced costs and improved patient outcomes and quantifies the relationship between adherence and outcomes.

\section{Data and methods}

The Truven Health Analytics MarketScan ${ }^{\circledR}$ Medicare Supplemental and Coordination of Benefits database supplied the data for this study. This database encompasses a geographically diverse population of Americans 65 years of age and older and contains patient demographics, enrollment information, and prescription drug, inpatient, and outpatient claims. The study data spanned the time period from July 1 , 2009 through June 30, 2014. All data were fully de-identified and compliant with the Health Insurance Portability and
Accountability Act. Given that the data is retrospective and fully de-identified, no institutional review board approval was required for the study as determined by the authors.

For inclusion in the study, patients were required to have received at least two diagnoses of T2D (International Classification of Diseases, Ninth Revision, Clinical Modification

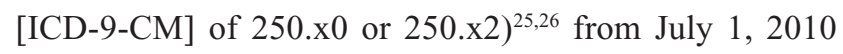
through June 30, 2011 (ie, the identification window), and to have received at least one prescription for a GLA over the identification window, with the date of the first such prescription designated as the index date. Additionally, patients were required to be at least aged 65 years as of the index date and to have had continuous insurance coverage from 1 year before (the preperiod) through 3 years after (the postperiod) the index date, as well as valid patient demographic data. Patients were excluded from the analyses if they received any diagnosis of type 1 diabetes (ICD-9-CM of 250.x1 or 250.x3) at any time from the start of the preperiod through the end of the postperiod. Figure 1 illustrates how each of these criteria affected sample size.

The analyses focused on the relationship between patient adherence and outcomes, where adherence was proxied by the PDC. PDC is a measure of adherence utilized by both the Pharmacy Quality Alliance and the Centers for Medicare and Medicaid services, ${ }^{27,28}$ and in this study it was constructed in

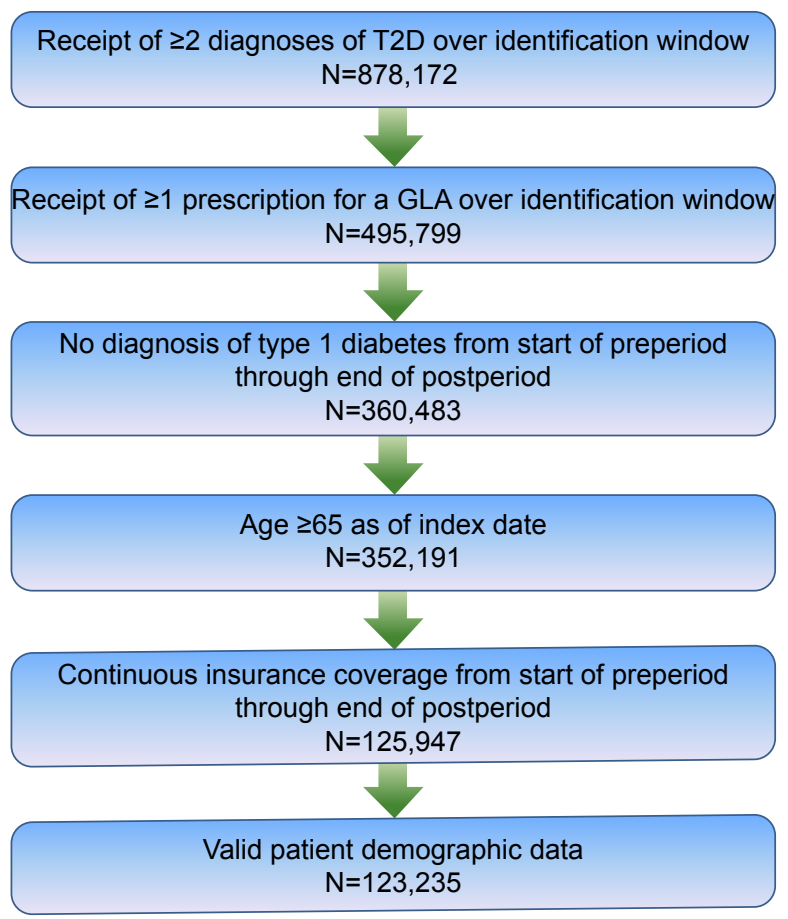

Figure I Inclusion-exclusion criteria and sample size.

Notes: Identification window defined as July I, 2010 through June 30, 20II. Index date defined as first receipt of GLA in identification window. Preperiod defined as I year prior to index date. Postperiod defined as 3 years plus index date. Abbreviations: GLA, glucose-lowering agent; T2D, type 2 diabetes. 
the present analyses as the percentage of days an individual received at least one GLA in the first year of the postperiod. While receipt of medication does not necessarily imply adherence to such therapy, PDC has been shown to be a conservative estimate of adherence in situations when the patient may use multiple medications or switch medications and data are only available via secondary database analysis. ${ }^{29}$ Furthermore, research has shown that for patients treated with monotherapy, PDC was the most conservative estimate of adherence among eight database measures constructed. ${ }^{30}$ Database proxies for adherence have also been shown to be directly related to patient outcomes. ${ }^{31,32}$ Consistent with previous research, $\mathrm{PDC}$ was categorized into quintiles. ${ }^{22}$ For all medications except insulin, PDC was constructed using the "days supplied" field provided in the database. For insulin, "days supplied" was calculated as the average number of days between fills for an insulin prescription. ${ }^{33}$

Outcomes of interest included costs, acute-care resource utilization, and acute complications. Both all-cause and diabetes-related costs were calculated, where diabetes-related costs were based upon receipt of diagnosis of diabetes (ICD-9-CM of 250.xx) or of a GLA. Costs were subdivided into acute care (hospitalization and ER), outpatient, drug, and total categories, and all costs were converted to 2014 prices using the medical component of the consumer price index. In all cases, costs were calculated using gross payments to a provider for a service. Acute-care resource utilization was defined as the probability of a hospitalization or an ER visit, the number of hospitalizations or ER visits, and the hospital length of stay (LOS). Acute complications were identified based upon receipt of a diagnosis of hyperglycemia (ICD-9-CM of 790.29), hypoglycemia (ICD-9-CM of 250.8, 251.0, 251.1, or 251.2), or diabetic or hypoglycemic coma (ICD-9-CM of 250.3, 251.0).

Multivariable analyses were used to examine the relationship between outcomes of interest and patient adherence. All analyses controlled for the individual patient's characteristics (age, sex, region of residence, and insurance coverage), preperiod general health status, comorbidities, medication use, and providers. General health was proxied by the Charlson Comorbidity Index, ${ }^{34,35}$ while the severity of a diabetes complication was proxied using the Diabetes Complications Severity Index. ${ }^{36}$ In addition, the models also included comorbidities that have been shown to be common in patients with diabetes and that were not captured in either the Charlson Comorbidity Index or Diabetes Complications Severity Index scores. Specifically, anxiety has been shown to be prevalent in patients with diabetes, ${ }^{37}$ comorbid depression has been shown to be linked to nonadherence, ${ }^{38}$ and hyperlipidemia has been used in previous studies which examined the relationship between adherence and outcomes. ${ }^{39}$ Therefore, this study included indicator variables for preperiod diagnoses of anxiety (ICD-9-CM of 300.xx except 300.3x and 300.4x), depression (ICD-9-CM of 296.2, 296.3, 300.4, or 311.xx), and hyperlipidemia (ICD9-CM of 272.1-272.4). The analyses also controlled for provider services in the 1-year preperiod, with indicator variables for visits to a cardiologist, endocrinologist, family medicine practitioner, internal medicine practitioner, or renal dialysis therapy. The analyses also controlled for the number and type of GLAs prescribed and overall medication used in the first 3 months of the postperiod. These factors were captured by indicator variables for insulin use, the number of non-GLA medications used, and the number of non-insulin classes of GLAs prescribed. The classes of non-insulin GLAs included $\alpha$-glucosidase inhibitors, amylin analogs, biguanides, dipeptidyl peptidase IV inhibitors, glucagon-like peptide-1 receptor agonists, meglitinides, sodium-glucose transporter-2s, sulfonylureas, thiazolidines, and oral fixed combinations.

General linear models with a gamma distribution and log link were used to examine all-cause and diabetes-related outpatient, drug, and total costs. Two-part models were used to examine acute-care costs, where the first part captured the probability of an all-cause or diabetes-related acute-care visit and the second part estimated costs among users of the service. Resource utilization was examined by estimating negative binomial regressions for the number of hospitalizations, the number of ER visits, and hospital LOS. Logistic regressions were used to examine the probability of hospitalization, ER use, or acute complication.

As a test of the sensitivity of the results, all analyses were re-estimated twice. First, the medication possession ratio (MPR) was used as an alternative measure of adherence. The MPR, defined as the number of doses dispensed in relation to the dispensing period, ${ }^{40}$ differs from PDC in that it does not have an upper bound of 1 as it allows for double-counting of medication coverage. Second, to control for the possibility of selection bias, an instrumental variables mode ${ }^{41}$ was estimated using copayments and coinsurance associated with GLAs prescribed in the first 3 months of the postperiod as instruments. Differences in the estimated outcomes were then examined by adherence thresholds. $t$-Tests were used to compare whether differences between any two quintiles were statistically significant, and a Bonferroni adjustment was used for multiple comparisons. All analyses were conducted using SAS, version 9.4 (SAS Institute Inc., Cary, NC, USA).

\section{Results}

Table 1 presents descriptive statistics for the 123,235 individuals in the study. The majority of the patients were 
Table I Descriptive statistics

\begin{tabular}{|c|c|c|}
\hline Variable & $\mathbf{N}$ or mean & $\%$ or SD \\
\hline \multicolumn{3}{|c|}{ Patient characteristics - defined at index date } \\
\hline Age (mean; SD) & 74.42 & 6.23 \\
\hline \multicolumn{3}{|l|}{ Sex } \\
\hline Male & 65,103 & 52.83 \\
\hline Female & 58,132 & 47.17 \\
\hline \multicolumn{3}{|l|}{ Region } \\
\hline Northeast & 18,568 & 15.07 \\
\hline North Central & 46,777 & 37.96 \\
\hline South & 32,745 & 26.57 \\
\hline West & 25,145 & 20.40 \\
\hline \multicolumn{3}{|l|}{ Insurance plan type } \\
\hline Comprehensive insurance & 63,486 & 51.52 \\
\hline Exclusive provider organization & 49 & 0.04 \\
\hline Health maintenance organization & 18,490 & 15.00 \\
\hline Point of service & 4,949 & 4.02 \\
\hline Preferred provider organization & 35,982 & 29.20 \\
\hline CDHP/HDHP & 279 & 0.23 \\
\hline \multicolumn{3}{|c|}{ General health and comorbidities in preperiod } \\
\hline Charlson Comorbidity Index (mean; SD) & 2.44 & 1.81 \\
\hline $\begin{array}{l}\text { Diabetes Complications Severity Index } \\
\text { (mean; SD) }\end{array}$ & 1.47 & 1.64 \\
\hline Anxiety & 2,529 & 2.05 \\
\hline Depression & 4,922 & 3.99 \\
\hline Hyperlipidemia & 40,138 & 32.57 \\
\hline \multicolumn{3}{|c|}{ Provider and prescriber visited in preperiod } \\
\hline Cardiologist & 37,015 & 30.04 \\
\hline Endocrinologist & 7,457 & 6.05 \\
\hline Family medicine & $6 I, 177$ & 49.64 \\
\hline Internal medicine & 58,528 & 47.49 \\
\hline Renal dialysis therapy & 103 & 0.08 \\
\hline \multicolumn{3}{|c|}{ Medication use in first 3 months of postperiod } \\
\hline Insulin & 14,498 & 11.76 \\
\hline $\begin{array}{l}\text { Number of non-insulin classes } \\
\text { (mean; SD) }\end{array}$ & 1.38 & 0.72 \\
\hline $\begin{array}{l}\text { Number of non-antidiabetic medications } \\
\text { (mean; SD) }\end{array}$ & 6.14 & 3.50 \\
\hline \multicolumn{3}{|l|}{ Outcomes in postperiod } \\
\hline Drug costs (mean; SD) & $\$ 12,456$ & 13,732 \\
\hline Acute-care costs (mean; SD) & $\$ 16,674$ & 42,810 \\
\hline Outpatient costs (mean; SD) & $\$ 18,904$ & 43,633 \\
\hline Total costs (mean; SD) & $\$ 48,034$ & 71,392 \\
\hline Diabetes-related drug costs (mean; SD) & $\$ 3,432$ & 4,470 \\
\hline $\begin{array}{l}\text { Diabetes-related acute-care costs } \\
\text { (mean; SD) }\end{array}$ & $\$ 6,319$ & 20,434 \\
\hline $\begin{array}{l}\text { Diabetes-related outpatient costs } \\
\text { (mean; SD) }\end{array}$ & $\$ 3,523$ & 8,607 \\
\hline Diabetes-related total costs (mean; SD) & $\$ 13,274$ & 23,902 \\
\hline \multicolumn{3}{|l|}{ Adherence in first year of postperiod } \\
\hline PDC (mean; SD) & 75.97 & 27.48 \\
\hline \multicolumn{3}{|l|}{ PDC quintiles } \\
\hline$<20 \%$ & 9,539 & $7.74 \%$ \\
\hline$\geq 20 \%-<40 \%$ & 7,148 & $5.80 \%$ \\
\hline$\geq 40 \%-<60 \%$ & $10,59 \mid$ & $8.59 \%$ \\
\hline$\geq 60 \%-<80 \%$ & 18,188 & $14.76 \%$ \\
\hline$\geq 80 \%$ & 77,769 & $63.11 \%$ \\
\hline
\end{tabular}

Abbreviations: $\mathrm{CDHP}$, consumer-directed health plan; HDHP, high-deductible health plan; PDC, proportion of days covered; SD, standard deviation. male $(52.83 \%)$, and the mean age was 74 years (standard deviation $=6.23$ ). Patients most commonly resided in the North Central (37.96\%) or Southern (26.57\%) regions of the country, and most were covered by comprehensive insurance $(51.52 \%)$ or a preferred provider organization $(29.20 \%)$. Nearly half of the patients visited a family $(49.64 \%)$ or internal medicine $(47.49 \%)$ physician in the preperiod, and they less frequently visited a cardiologist $(30.04 \%)$ or endocrinologist $(6.05 \%)$. Nearly one in eight patients $(11.76 \%)$ received a prescription for insulin in the first 3 months of the postperiod, and patients were prescribed, on average, 1.38 non-insulin classes of GLAs and 6.14 nonGLA medications over this same time period. The majority of patients had a PDC of $\geq 80 \%$ (63.11\%). The mean PDC for this patient population was $75.97 \%$.

Figures 2 and 3 focus on the association between adherence to GLAs and costs. The results shown in Figure 2 revealed that at higher adherence levels, all-cause acute care and outpatient costs declined significantly. For example, for patients with adherence $<20 \%$, mean outpatient and acute-care costs were $\$ 28,086$ and $\$ 32,340$, respectively, while for patients with adherence $\geq 80 \%$, these mean costs were $\$ 17,298$ and $\$ 13,373(P<0.005)$. All-cause drug costs were highest for those with the lowest and highest adherence levels, and these costs significantly increased once an adherence level of $20 \%$ or above was reached. Three-year, all-cause, total costs exhibited a similar pattern to acute-care costs and outpatient costs, with higher adherence levels associated with significant cost reductions. Specifically, over the 3-year postperiod, all-cause total costs declined monotonically from $\$ 73,009$ (at adherence level PDC $<20 \%$ ) to $\$ 57,887$ (PDC $\geq 20 \%-<40 \%$ ), $\$ 52,446$ ( $\mathrm{PDC} \geq 40 \%-<60 \%), \$ 48,284$ (PDC $\geq 60 \%-<80 \%$ ), and $\$ 44,185$ (PDC $\geq 80 \%$; all $P<0.005$ ). Diabetes-related costs, as shown in Figure 3, generally exhibited the same pattern as all-cause costs. Namely, both diabetes-related acute care and outpatient costs significantly lessened at higher adherence levels, while diabetes-related drug costs increased once an adherence level of $20 \%$ was reached. As with all-cause total costs, diabetes-related total costs significantly decreased when moving from adherence threshold of PDC $<20 \%$ $(\$ 17,447)$ to $\mathrm{PDC} \geq 60 \%-<80 \%(\$ 12,716)(P<0.005)$. However, there was no statistically significant difference in diabetes-related total costs when comparing patients with PDC $\geq 60 \%-<80 \%$ to those with PDC $\geq 80 \%$ (\$12,716 vs $\$ 12,788 ; P=0.1734)$.

While Figures 2 and 3 examine costs, Table 2 focuses on the associations among adherence, resource utiliza- 


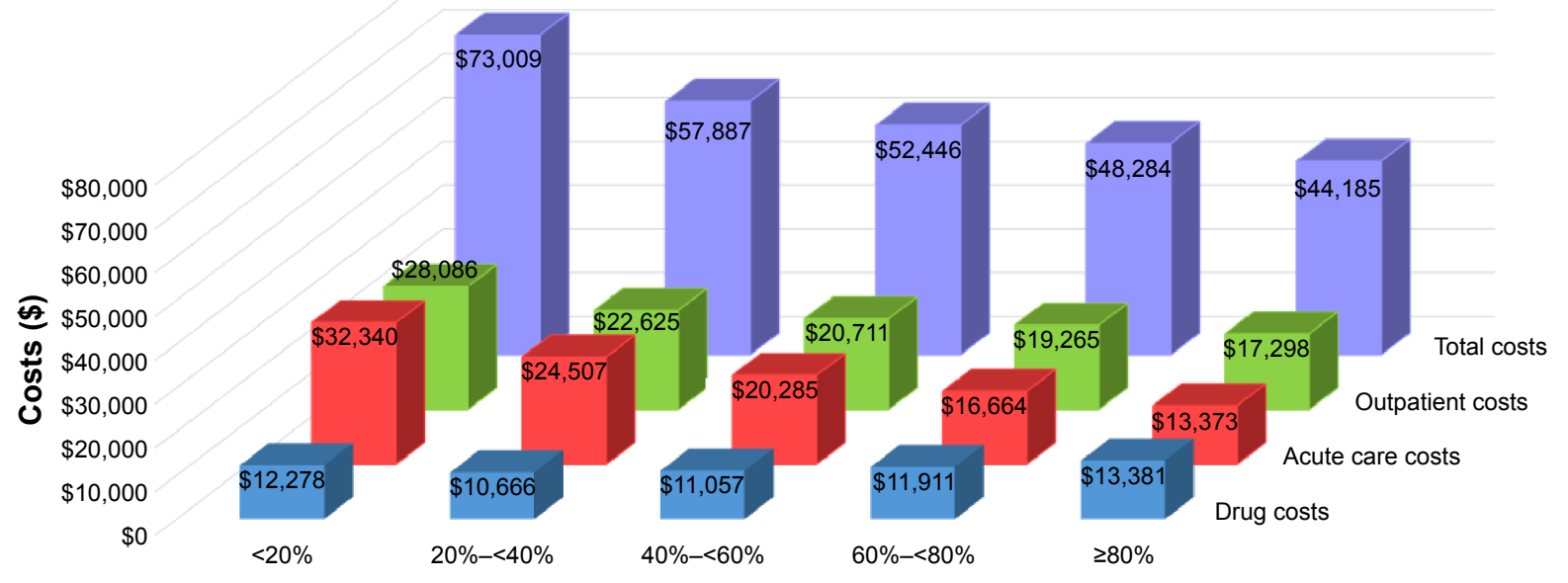

Proportion of days covered (PDC)

Drug costs $\square$ Acute care costs $\square$ Outpatient costs $\square$ Total costs

Figure 2 All-cause costs: by adherence levels. ${ }^{a}$

Note: at-Tests comparing component costs across alternative thresholds were all statistically significant $(P<0.05)$.

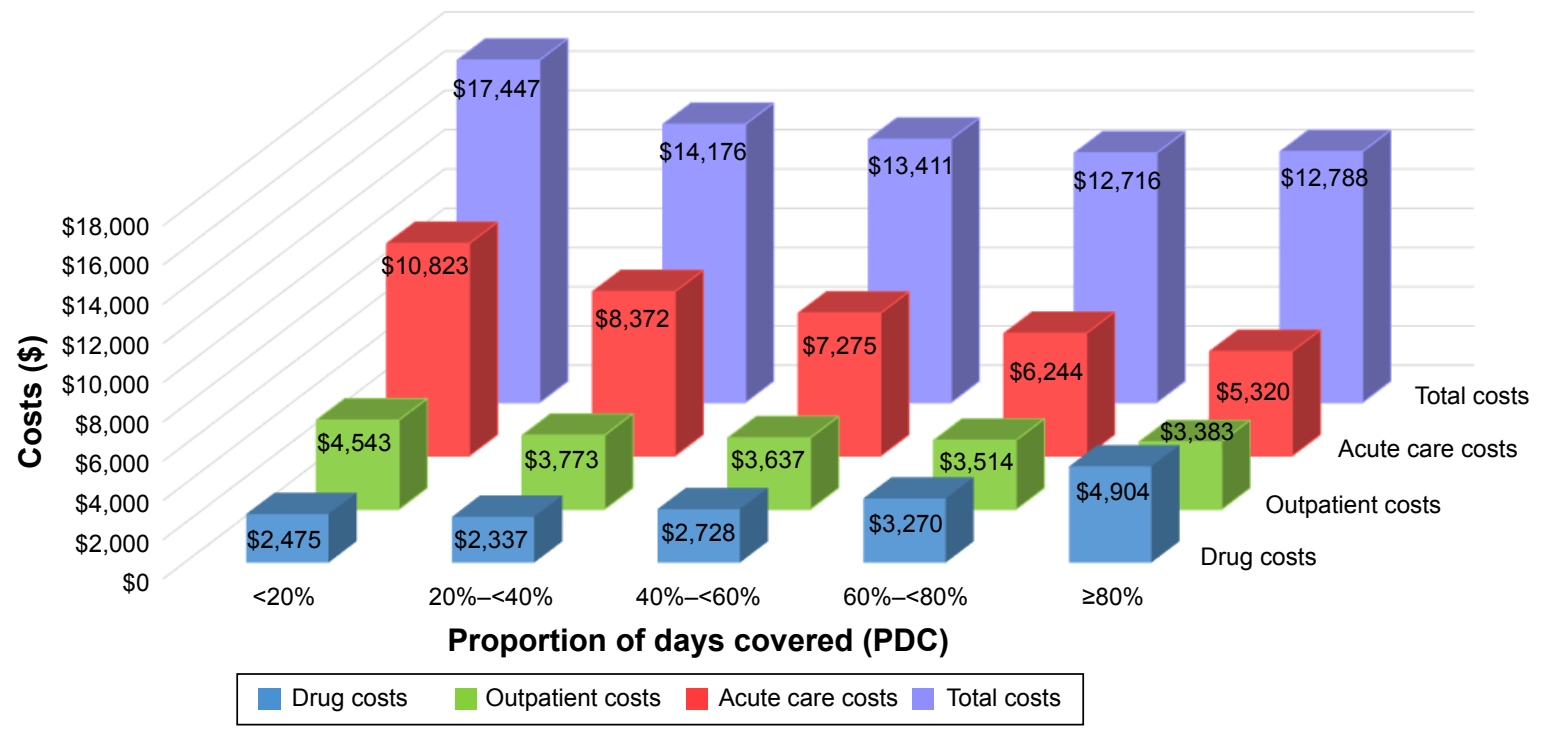

Figure 3 Diabetes-related costs: by adherence levels. ${ }^{a}$

Note: at-Tests comparing component costs across alternative thresholds were all statistically significant $(P<0.05)$ except: diabetes-related total costs with adherence level $60 \%-<80 \%$ compared to adherence level $\geq 80 \%$.

Table 2 Resource utilization and complications: by adherence levels ${ }^{\mathrm{a}}$

\begin{tabular}{|c|c|c|c|c|c|c|c|c|c|c|}
\hline \multirow[t]{2}{*}{ Outcome } & \multicolumn{2}{|l|}{$\begin{array}{l}\text { PDC } \\
<20 \%\end{array}$} & \multicolumn{2}{|c|}{$\begin{array}{l}\text { PDC } \\
\geq 20 \%-<40 \%\end{array}$} & \multicolumn{2}{|c|}{$\begin{array}{l}\text { PDC } \\
\geq 40 \%-<60 \%\end{array}$} & \multicolumn{2}{|c|}{$\begin{array}{l}\text { PDC } \\
\geq 60 \%-<80 \%\end{array}$} & \multicolumn{2}{|l|}{$\begin{array}{l}\text { PDC } \\
\geq 80 \%\end{array}$} \\
\hline & Mean & SD & Mean & SD & Mean & SD & Mean & SD & Mean & SD \\
\hline Probability of hospitalization (\%) & 56.22 & 16.28 & 50.05 & 15.56 & 45.45 & 15.44 & 41.44 & 14.93 & 37.43 & 13.77 \\
\hline Probability of ER visit (\%) & 72.09 & 13.23 & 66.58 & 13.48 & 62.40 & 14.07 & 58.57 & 14.29 & 54.18 & 13.85 \\
\hline Number of hospitalizations & 1.26 & 0.86 & 0.99 & 0.61 & 0.83 & 0.51 & 0.71 & 0.43 & 0.60 & 0.33 \\
\hline Number of ER visits & 3.37 & 2.40 & 2.57 & $\mathrm{I} .64$ & 2.16 & 1.37 & 1.82 & 1.12 & 1.50 & 0.85 \\
\hline Hospital LOS & 8.71 & 7.15 & 6.19 & 4.62 & 4.84 & 3.55 & 3.82 & 2.78 & 3.00 & 1.97 \\
\hline Probability of acute complication (\%) & 24.11 & 13.86 & 18.19 & 10.48 & 16.26 & 9.71 & 14.47 & 8.92 & 13.02 & 8.17 \\
\hline
\end{tabular}

Note: ${ }^{a}$-Tests comparing resource utilization and complications across alternative thresholds were all statistically significant $(P<0.00 \mathrm{I})$.

Abbreviations: ER, emergency room; LOS, length of stay; PDC, proportion of days covered; SD, standard deviation. 
tion, and complications. The results displayed in Table 2 revealed that, in all cases, higher adherence was associated with significant improvements in patient outcomes. Both the probability of hospitalization and the probability of an ER admission decreased monotonically as a function of higher adherence. For example, as adherence moved by quintiles from PDC $<20 \%$ to $\mathrm{PDC} \geq 80 \%$, the probability of hospitalization declined from $56.22 \%$ to $50.05 \%, 45.45 \%, 41.44 \%$, and $37.43 \%$, respectively (all $P<0.001$ ). Similarly, higher adherence levels were associated with significantly diminished number of hospitalizations, number of ER visits, and hospital LOS. Finally, over the 3-year postperiod, the likelihood of an acute complication also significantly decreased as adherence thresholds got higher, declining from $24.11 \%$ for patients with PDC $<20 \%$ to $13.02 \%$ for patients with $\mathrm{PDC} \geq 80 \%(P<0.001)$.

Results were generally not sensitive to using MPR as an alternative measure of adherence or using an instrumental variable model. However, when utilizing instrumental variables, diabetes-related total costs were not significantly different when comparing patients with $\mathrm{PDC} \geq 40 \%-<60 \%$ to those with $\mathrm{PDC} \geq 80 \%$ ( $\$ 13,023$ vs $\$ 13,038 ; P=0.8377)$, while this difference was statistically significant in our primary analyses $(\$ 13,411$ vs $\$ 12,788 ; P<0.005)$. Meanwhile, where the MPR model varied from the primary analysis, it amplified the benefits of GLA adherence, showing PDC to be the more conservative of the two measures. For instance, comparing results for adherence thresholds of MPR $\geq 60 \%-<80 \%$ to MPR $\geq 80 \%$ (\$14,107 vs $\$ 12,320$; $P<0.0001)$, the diabetes-related total costs significantly decreased, whereas this difference was not statistically significant when PDC was used as the proxy for adherence ( $\$ 12,716$ vs $\$ 12,788 ; P=0.1734)$. Furthermore, when MPR was used as the adherence measure, there were fewer statistically significant differences in all-cause drug costs across alternative adherence thresholds, such that patients who had an adherence threshold of MPR $20 \%-<40 \%$ $(\$ 12,694)$ had all-cause drug costs that were not significantly different from patients at adherence thresholds of MPR 40\%-<60\% (\$12,833, $P=0.4441)$, MPR 60\%-<80\% (\$12,614, $P=0.6321)$, or MPR $\geq 80 \%(\$ 12,523, P=0.2719)$; additionally, all-cause drug costs for patients with an adherence threshold of MPR $60 \%-<80 \%(\$ 12,614)$ were not significantly different compared to patients with thresholds of MPR $40 \%-<60 \%(\$ 12,833, P=0.0603)$, or MPR $\geq 80 \%$ $(\$ 12,523, P=0.1901)$.

\section{Discussion}

In support of earlier research, ${ }^{17,24}$ this study of older Americans with T2D demonstrated that higher PDC, used as a proxy for GLA adherence, was associated with substantially beneficial economic and humanistic outcomes. In addition, the present investigation furthered the previous literature through its broad scope (ie, a large sample size, all classes of GLAs, and a 3-year follow-up period) and relatively current, naturalistic data. Moreover, to ensure the reliability of the findings, this study employed a variety of methods, which ranged from re-estimating the analyses twice using alternative models to using a comparatively conservative proxy for adherence (PDC) and to controlling for a wide range of factors that may affect patient outcomes. Given all of these strengths, the following sections discuss the study results within the context of previous evidence.

\section{All-cause and diabetes-related costs}

Consistent with a number of previous investigations, ${ }^{14,17,20-23}$ the present study showed that higher GLA adherence rates were associated with extensive decreases in total medical costs.

Furthermore, as shown in earlier research, ${ }^{42}$ these total cost reductions were driven by the lessening of acute-care costs related to higher adherence, even though higher adherence was associated with higher drug costs. Although diabetes-related drug spending tended to increase at higher adherence levels, these higher drug-related expenditures were more than offset by reductions in all other cost categories including decreases in other diabetes-related costs (acute care, outpatient, and total), as well as falloffs in all-cause acute care and all-cause outpatient spending. This evidence provides a strong value statement for GLA therapy and a persuasive financial incentive for older T2D patients to adhere to their GLA treatment regimen. Previous research has reported that higher GLA adherence is linked to larger cost savings for patients 65 years and older relative to younger adults. ${ }^{17}$

Generally consistent with an earlier investigation, ${ }^{22}$ another noteworthy observation from the present analysis was that all-cause costs decreased successively with every progression to a higher adherence quintile, whereas diabetesrelated costs decreased as adherence thresholds moved from PDC $<20 \%$ to $\mathrm{PDC} \geq 60 \%-<80 \%$ and remained the same, in statistical terms, when comparing adherence thresholds of PDC $\geq 60 \%-<80 \%$ to $\mathrm{PDC} \geq 80 \%$. While the majority of patients had a PDC of $\geq 80 \%$, higher adherence was associated with substantial cost savings. Comparing patients from the lowest (PDC $<20 \%$ ) to the highest (PDC $\geq 80 \%$ ) 
category of adherence was associated with all-cause costs savings of $\$ 28,824$ over the 3-year postperiod, or $\$ 9,608$ savings per year. However, even small changes in adherence were related to relatively large reductions in costs. For example, a $1 \%$ increase in adherence was associated with, on average, in all-cause cost savings of $\$ 65,464$ among 1,000 patients, or $\$ 8,067,507$ among all 123,235 individuals, over the 3-year postperiod.

\section{Acute-care resource use}

Supporting the findings of a number of earlier studies, ${ }^{12-17}$ this investigation also revealed a strong link between higher adherence and reduced use of acute-care resources. Specifically, comparing a patient in the least adherent quintile to one in the most-adherent quintile illustrates that the most-adherent patient would have an $18.79 \%$ reduction in the probability of a hospitalization, a $17.91 \%$ reduction in the probability of an ER visit, half the number of hospitalizations, half the number of ER visits, and approximately a third of the hospital LOS. Such a decreased use of acute care is consistent with the lower acute-care costs observed among the more adherent patients in this study. In turn, these lower acute-care costs were the major driver of the reduced total medical costs seen among those with higher adherence. For instance, over the 3-year postperiod, a patient in the most-adherent group had, on average, $\$ 18,967$ lower acute-care costs relative to a patient in the least adherent segment, as compared to savings of approximately half that amount, or $\$ 10,788$, in the outpatient cost category. These findings are consistent with national data, which have indicated that just one component of acute care, hospitalization, accounts for $43 \%$ of all diabetes-related costs and that individuals aged 65 years or older use more diabetes services in general and more inpatient days in particular compared to those younger than 65 years. ${ }^{10}$

In addition to being a key contributor to total health care costs, acute care has significant humanistic implications. Unlike routine outpatient treatment and medication use, which indicate planned activities and forward momentum, acute care is often unpredictable and may be traumatic for patients. Moreover, acute care tends to have particularly adverse consequences for older adults. Specifically, in the 6 months after discharge from the ER, senior Americans have a high likelihood of ER readmission, hospitalization, loss of physical functioning and independence, and death. ${ }^{43}$ Meanwhile, even short hospital stays can often lead to subsequent hospital stays or to long-term institutionalization for older patients, who are prone to muscle atrophy due to prolonged bed rest and acute illness contracted during hospitalization. ${ }^{44}$ Furthermore, it has been suggested that disease-oriented and episodic models of ER care may not be adequate for older patients, who are often frail and have complex medical needs. ${ }^{45}$ As such, the acute-care findings of the present study support survey-based evidence indicating that older diabetes patients with higher GLA adherence have less emotional distress and a better overall quality of life relative to their less adherent peers. ${ }^{24}$

\section{Complications}

Guidelines for the management of diabetes among older individuals state that prevention and management of diabetesrelated complications should become a priority. ${ }^{11}$ To this end, the present study focused on the relationship between adherence and acute complications, including hyperglycemia, hypoglycemia, and diabetic or hypoglycemic coma, among T2D patients. Particularly common among older T2D patients, ${ }^{11}$ hypoglycemia, when severe, can lead to coma, stroke, bone fracture (caused by convulsions or a fall), or death. ${ }^{45}$ Fears of hypoglycemia and its consequences have been reported to be a barrier to patient adherence to GLA therapy. ${ }^{46}$ Contrary to such fears, as well as to previous literature reporting that GLA therapy is a risk factor for hypoglycemia, ${ }^{45,46}$ the present findings suggest that higher adherence to GLAs among older T2D patients is associated with a lower rate of acute complications, including decreased odds of hyperglycemia, hypoglycemia, or diabetic or hypoglycemic coma. All differences across adherence quintiles were statistically significant, suggesting that even incremental improvements in adherence may substantially lower the risk of an acute complication. As an individual with fewer acute complications would likely require less acute care, these findings are consistent with the diminished need for acute care observed among this study's patients with higher adherence. In addition, these results generally support previous research that focused on other types of chronic complications (eg, microvascular or macrovascular disorders) and found that higher adherence was associated with diminished odds of developing such complications. ${ }^{13,18,19}$

\section{Limitations}

The findings of this study must be interpreted within the context of the study limitations. The analyses were based upon observational health insurance claims data from a Medicare Supplemental database. As a result, the findings may not generalize to the population of all older patients. Second, 
adherence was not directly measured and, hence, was proxied by PDC. The use of PDC as a proxy for adherence is an indirect measure that fails to identify partial adherence and assumes that filling of a prescription corresponds to medication being taken according to prescription. Furthermore, our proxy for adherence is unable to capture any prescriptions taken outside of the insurance system and will not capture any discontinuations advised by the prescriber. Third, the use of diagnostic codes is not as rigorous as formal assessments and may have underrepresented certain conditions, such as hypoglycemia. Fourth, the analyses did not allow for an examination of complications or other outcomes over the long-term. Fifth, the use of claims data did not allow controlling for nondocumented factors, such as race, duration of diabetes, and socioeconomic class, any of which may also be associated with patient outcomes. Finally, the analyses focused on statistical significance and we were unable to determine whether differences in outcomes represented minimal clinically important changes.

\section{Conclusion}

In sum, in this study of older T2D patients with Medicare supplemental insurance, higher PDC, used as a proxy for adherence, was associated with substantially less need for acute care, as indicated by a lowered probability of hospitalization or ER use, as well as by a decreased number of hospitalizations, ER visits, and days hospitalized. This reduced use of acute-care services may be especially beneficial for older patients, given the frailty and the complex health status often found in this population. In addition, better adherence was linked to a lessened risk of an acute complication. Consistent with these findings, higher adherence was associated with decreased acute-care costs and outpatient costs, as well as lower total costs (all-cause and diabetes-related). While drug expenditures tended to increase with higher adherence, such escalations were more than offset by the reductions in the other cost categories. Furthermore, even small changes in patient adherence were found to have potentially large cost implications, with a $1 \%$ increase in adherence associated with cost savings of $\$ 65,464$ for just 1,000 individuals, or $\$ 8,067,507$ for the entire population, over the 3-year postperiod. The results of this study suggest higher adherence among older T2D patients is associated with significant economic and humanistic benefits.

\section{Acknowledgment}

The authors would like to thank Patricia Platt for her assistance in the writing of the manuscript.

\section{Disclosure}

Boye, Curtis, and Garcia-Perez are shareholders and employees of Eli Lilly and Company. Lage was compensated for her work on this project by Eli Lilly and Company. The authors report no other conflicts of interest in this work.

\section{References}

1. United Nations, Department of Economic and Social Affairs, Population Division. World Population Ageing: 2013. ST/ESA/SER.A/348. 2013. Available from: http://www.un.org/en/development/desa/population/ publications/pdf/ageing/WorldPopulationAgeing2013.pdf. Accessed April 27, 2016.

2. Centers for Disease Control and Prevention. The State of Aging and Health in America 2013. Atlanta, GA: Center for Disease Control and Prevention, US Dept of Health and Human Services; 2013. Available from: http://www.cdc.gov/features/agingandhealth/state_of_aging and_health_in_america_2013.pdf. Accessed April 27, 2016.

3. United States Census Bureau. National population projections: summary tables; 2013. Available from: http://www.census.gov/population/ projections/data/national/2012/summarytables.html. Accessed March 1, 2016.

4. American Heart Association. Understand your risk for diabetes: non-modifiable risk factors for type 2 diabetes; 2016. Available from: http://www.heart.org/HEARTORG/Conditions/Diabetes/ UnderstandYourRiskforDiabetes/Understand-Your-Risk-for-Diabetes_UCM_002034_Article.jsp\#.VtXhJ2fSmUk. Accessed March 1, 2016.

5. World Health Organization. Diabetes mellitus. Fact sheet no 138; 2016. Available from: http://www.who.int/mediacentre/factsheets/en/. Accessed March 1, 2016.

6. Centers for Disease Control and Preventions. National Diabetes Statistics Report: Estimates of Diabetes and Its Burden in the United States, 2014. Atlanta, GA: U.S. Department of Health and Human Services; 2014. Available from: http://www.cdc.gov/diabetes/pubs/statsreport14/ national-diabetes-report-web.pdf. Accessed March 1, 2016.

7. Kirkman MS, Briscoe VJ, Clark N, et al; Consensus Development Conference on diabetes and older adults. Diabetes in older adults: a consensus report. J Am Geriatr Soc. 2012;60(12):2342-2356.

8. Brown AF, Mangione CM, Saliba D, Sarkisian CA; California Healthcare Foundation/American Geriatrics Society Panel in improving care for elders with diabetes. Guidelines for improving the care of the older person with diabetes mellitus. J Am Geriatr Soc. 2003;51(5s):S265-S280.

9. Bertoni AG, Krop JS, Anderson GF, Brancati FL. Diabetes-related morbidity and mortality in a national sample of U.S. elders. Diabetes Care. 2002;25(3):471-475.

10. American Diabetes Association. Economic costs of diabetes in the U.S. in 2012. Diabetes Care. 2013;36(4):1033-1046.

11. Sinclair A, Morley JE, Rodriguez-Mañas L, et al. Diabetes mellitus in older people: position statement on behalf of the International Association of Gerontology and Geriatrics (IAGG), the European Diabetes Working Party for Older People (EDWPOP), and the International Task Force of experts in diabetes. J Am Med Dir Assoc. 2012;13(6):497-502.

12. Cheng SH, Chen CC, Tseng CH. Does medication adherence lead to lower healthcare expenses for patients with diabetes? Am J Manag Care. 2013;19(8):662-670.

13. Gibson TB, Song X, Alemayehu B, et al. Cost sharing, adherence, and health outcomes in patients with diabetes. Am JManag Care. 2010;16(8): 589-600.

14. Encinosa WE, Bernard D, Dor A. Does prescription drug adherence reduce hospitalizations and costs? The case of diabetes. Adv Health Econ Health Serv Res. 2010;22:151-173.

15. Jha AK, Aubert RE, Yao J, Teagarden JR, Epstein RS. Greater adherence to diabetes drugs is linked to less hospital use and could save nearly \$5 billion annually. Health Aff (Millwood). 2012;31(8):1836-1846. 
16. Juarez DT, Tan C, Davis J, Mau M. Factors affecting sustained medication adherence and its impact on health care utilization in patients with diabetes. J Pharm Health Serv Res. 2013;4(2):89-94.

17. Roebuck MC, Liberman JN, Gemmill-Toyama M, Brennan TA. Medication adherence leads to lower health care use and costs despite increased drug spending. Health Aff (Millwood). 2011;30(1):91-99.

18. Park IS, Sohn HS. Effect of medicine adherence on the occurrence of cerebrovascular disorders in diabetes mellitus patients. Epidemiol Health. 2011;33:e2011001.

19. Yu AP, Yu YF, Nichol MB. Estimating the effect of medication adherence on health outcomes among patients with type 2 diabetes - an application of marginal structural models. Value Health. 2010;13(8):1038-1045.

20. Hansen RA, Farley JF, Droege M, Maciejewski ML. A retrospective cohort study of economic outcomes and adherence to monotherapy with metformin, pioglitazone, or a sulfonylurea among patients with type 2 diabetes mellitus in the United States from 2003 to 2005. Clin Ther. 2010; 32(7):1308-1319.

21. Hong JS, Kang HC. Relationship between oral antihyperglycemic medication adherence and hospitalization, mortality, and healthcare costs in adult ambulatory care patients with type 2 diabetes in South Korea. Med Care. 2011;49(4):378-384.

22. Sokol MC, McGuigan KA, Verbrugge RR, Epstein RS. Impact of medication adherence on hospitalization risk and healthcare cost. Med Care. 2005;43(6):521-530.

23. Wong ES, Bryson CL, Hebert PL, Liu CF. Estimating the impact of oral diabetes medication adherence on medical costs in VA. Ann Pharmacother. 2014;48(8):978-985.

24. Manan MM, Husin AR, Alkhoshaiban AS, Al-Worafi YMA, Ming LC. Interplay between oral hypoglycemic medication adherence and quality of life among elderly type 2 diabetes mellitus patients. J Clin Diagn Res. 2014;8(12):JC05-JC09.

25. Kheirbek RE, Alemi F, Zargoush M. Comparative effectiveness of hypoglycemic medications among veterans. J Manag Care Pharm. 2013; 19(9):740-744.

26. Malmenäs M, Bouchard JR, Langer J. Retrospective real-world adherence in patients with type 2 diabetes initiating once-daily liraglutide $1.8 \mathrm{mg}$ or twice-daily exenatide $10 \mu \mathrm{g}$. Clin Ther. 2013;35(6):795-807.

27. Centers for Medicare \& Medicaid Services. Health Insurance Marketplace Quality Rating Systems Measure Technical Specifications; 2014. Available from: https://www.cms.gov/Medicare/QualityInitiatives-Patient-Assessment-Instruments/QualityInitiativesGenInfo/ Downloads/2015-QRS-Measure-Technical-Specifications.pdf. Accessed March 1, 2016.

28. Pharmacy Quality Alliance. PQA medication quality measures in the health insurance marketplace; 2015. Available from: http://pqaalliance. org/measures/qrs.asp. Accessed March 1, 2016.

29. Martin BC, Wiley-Exley Ek, Richards S, Domino ME, Carey Ts, Sleath BL. Contrasting measures of adherence with simple drug use, medication switching, and therapeutic duplication. Ann Pharmacother. 2009; 43(1):36-44.

30. Karve S, Cleves MA, Helm M, Hudson TJ, West DS, Martin BC. Prospective validation of eight different adherence measures for use with administrative claims data among patients with schizophrenia. Value Health. 2009;12(6):989-995.
31. Krousel-Wood M, Holt E, Cara J, et al. Differences in cardiovascular disease risk when antihypertensive medication adherence is assessed by pharmacy fill versus self-report: the Cohort Study of Medication Adherence among Older Adults (CoSMO). J Hypertens. 2015; 33(2):412-420.

32. Pladevall M, Williams LK, Potts LA, Divine G, Xi H, Lafata JE. Clinical outcomes and adherence to medications measured by claims data in patients with diabetes. Diabetes Care. 2004;27(12):2800-2805.

33. Baser O, Bouchard J, DeLuzio T, Henk H, Aagren M. Assessment of adherence and healthcare costs of insulin device (FlexPen) versus conventional vial/syringe. Adv Ther. 2010;27(2):94-104.

34. Deyo RA, Cherkin DC, Ciol MA. Adapting a clinical comorbidity index for use with ICD-9-CM administrative databases. J Clin Epidemiol. 1992; 45(6):613-619.

35. Quan H, Sundararajan V, Halfon P, et al. Coding algorithms for defining comorbidities in ICD-9-CM and ICD-10 administrative data. Med Care. 2005;43(11):1130-1139.

36. Chang HY, Weiner JP, Richards TM, Bleich SN, Segal JB. Validating the adapted Diabetes Complications Severity Index in claims data. Am J Manag Care. 2012;18(11):721-726.

37. Grigsby AB, Anderson RJ, Freedland KE, Clouse RE, Lustman PJ. Prevalence of anxiety in adults with diabetes: a systematic review. J Psychosom Res. 2002;53(6):1053-1060.

38. Gonzalez JS, Peyrot M, McCarl LA, et al. Depression and diabetes treatment nonadherence: a meta-analysis. Diabetes Care. 2008;31(12): 2398-2403.

39. Ayyagari R, Wei W, Cheng D, Pan C, Signorovitch J, Wu EQ. Effect of adherence and insulin delivery system on clinical and economic outcomes among patients with type 2 diabetes initiating insulin treatment. Value Health. 2015;18(2):198-205.

40. Cramer JA, Roy A, Burrell A, et al. Medication compliance and persistence: terminology and definitions. Value Health. 2008;11(1):44-47.

41. McClellan M, McNeil BJ, Newhouse JP. Does more intensive treatment of acute myocardial infarction in the elderly reduce mortality? Analysis using instrumental variables. JAMA. 1994;272(11):859-866.

42. Breitscheidel L, Stamenitis S, Dippel FW, Schöffski O. Economic impact of compliance to treatment with antidiabetes medication in type 2 diabetes mellitus: a review paper. J Med Econ. 2010;13(1):8-15.

43. Aminzadeh F, Dalziel WB. Older adults in the emergency department: a systematic review of patterns of use, adverse outcomes, and effectiveness of interventions. Ann Emerg Med. 2002;39(3):238-247.

44. English KL, Paddon-Jones D. Protecting muscle mass and function in older adults during bed rest. Curr Opin Clin Nutr Metab Care. 2010; 13(1):34-39.

45. Zammitt NN, Frier BM. Hypoglycemia in type 2 diabetes: pathophysiology, frequency, and effects of different treatment modalities. Diabetes Care. 2005;28(12):2948-2961.

46. Ahren B. Avoiding hypoglycemia: a key to success for glucoselowering therapy in type 2 diabetes. Vasc Health Risk Manag. 2013:9: $155-163$.
Patient Preference and Adherence

\section{Publish your work in this journal}

Patient Preference and Adherence is an international, peer-reviewed, open access journal that focuses on the growing importance of patient preference and adherence throughout the therapeutic continuum. Patient satisfaction, acceptability, quality of life, compliance, persistence and their role in developing new therapeutic modalities and compounds to optimize

\section{Dovepress}

clinical outcomes for existing disease states are major areas of interest for the journal. This journal has been accepted for indexing on PubMed Central. The manuscript management system is completely online and includes a very quick and fair peer-review system, which is all easy to use. Visit http://www. dovepress.com/testimonials.php to read real quotes from published authors. 